\title{
Water Hammer and Column Separation Induced by Simultaneous and Delayed Closure of Two Valves
}

\author{
Uroš Karadžić1, ${ }^{*}$ - Marko Janković 2 - Filip Strunjaš3 ${ }^{3}$ - Anton Bergant ${ }^{4}$ \\ 1University of Montenegro, Faculty of Mechanical Engineering, Montenegro \\ 2Electric Power Supply Company, Montenegro \\ 3 Kone, Montenegro \\ ${ }^{4}$ Litostroj Power d.o.o., Slovenia
}

Water hammer and column separation induced by simultaneous and sequential (delayed) closure of two valves may occur in industrial pipeline systems. This paper deals with such cases both experimentally and numerically. Water hammer equations are solved by the method of characteristics. Transient cavitating pipe flow is simulated by a discrete gas cavity model (DGCM) that considers unsteady skin friction. Discrete gas cavities and Zielke's convolution-based unsteady skin friction term are explicitly incorporated in the staggered grid algorithm of the method of characteristics. Experiments have been performed in a laboratory pipeline apparatus. The apparatus consists of an upstream end tank, a horizontal steel pipeline (total length $55.37 \mathrm{~m}$, inner diameter $18 \mathrm{~mm}$ ), four valve units positioned along the pipeline including the end points, and a downstream end tank. A transient event is induced either by simultaneous or sequential closure of two end valves. Numerical results are compared and verified with results of measurements. In addition, a theoretical analysis of pressure wave fronts travelling along the pipeline is also presented to clearly show profound effects of wave interactions.

Keywords: pipeline, two valves, simultaneous and delayed valve closure, water hammer, column separation, experimental setup, unsteady friction

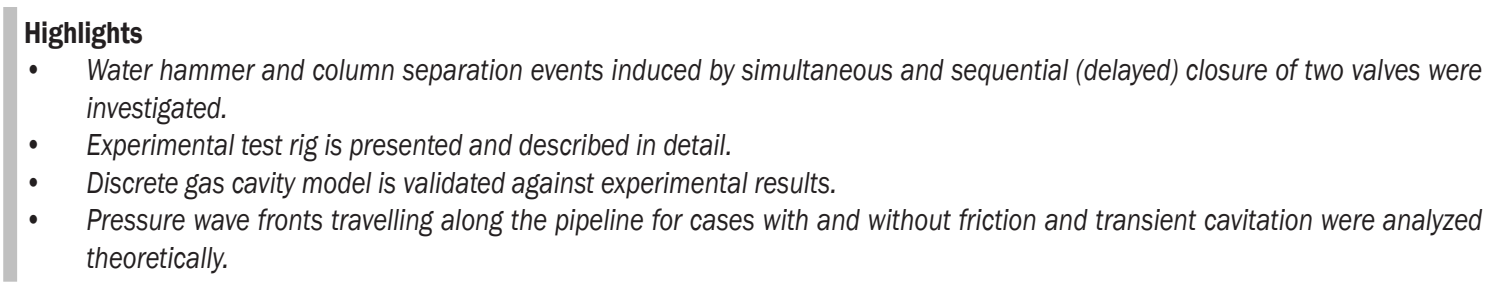

\section{O INTRODUCTION}

The term hydraulic transients means a process that takes place in a physical system during the transition from one to another steady state. Knowledge of hydraulic transients and conditions that cause extreme pressures are crucial for safe and economical design of hydraulic systems. Hydraulic transients occur during opening and closing of control valves and changing of the operating mode of hydraulic turbomachinery such as turbo pumps and water turbines [1] and [2]. As a result of these changes high or low pressures are formed and transferred through the hydraulic pipe system with a speed which is close to the speed of sound in liquids. The local speed of sound is defined by the physical condition of the liquid (free air content) and pipe wall (rigid, elastic) and usually is variable in time and space. Pressure waves may have such intensity that they can lead to serious malfunctions of hydraulic system equipment and can cause significant damages and even breakdown of system components. To prevent unwanted effects of hydraulic transient events, pipeline systems must be fitted with adequate protective surge control means. The term water hammer is a synonym for rapid unsteady flow in pipelines and was named after the characteristic sound that occurs during the unsteady event and sounds like strikes with a hammer.

For understanding water hammer phenomena, except pressure changes, fluid compressibility and pipeline mechanics must be considered [1] and [2]. The side effects of water hammer are transient cavitation and column separation, unsteady skin friction, fluidstructure interaction (FSI) and viscoelastic behaviour of the pipe wall [3]. During transient events, it may happen that liquid pressure drops to the liquid vapour pressure. In this case vapour bubbles form [4]. Liquid also contains a certain amount of free and dissolved gas, and if the value of pressure in the system drops below the gas saturated pressure it leads to gas releasing from the liquid and the occurrence of gaseous cavitation [5]. Thus, formed vapour and gas bubbles can coalesce, form large pockets and cause separation of the liquid flow in the pipeline (column separation). The positive pressure waves reflected from the system boundaries (e.g., reservoir, valve, 
turbine, pump, etc.), compress the bubbles in the cavitation-flow region and progressively reduce the size of the cavity produced by column separation [4]. Cavities collapse and the re-joining of separated columns may produce very high pressures higher than the pressure initially given by the Joukowsky equation and may cause damage of the system components [1]. The value of the friction factor, which describes the resistance due to pipe-wall friction during transients, is different from its value for the steady state flow. For fast transients, the friction coefficient $f$ can be expressed as the sum of two parts: the quasi-steady part $\left(f_{q}\right)$ and the unsteady part $\left(f_{u}\right)$ [6] to [8]. The unsteady part attempts to represent velocity profile changes and flow regime conversions from laminar to turbulent and vice versa [9] to [10].

The objective of this paper is to investigate and discuss water hammer and column separation effects induced by simultaneous and sequential (delayed) closure of two end valves in a simple pipeline apparatus. There are many industrial pipeline systems with multiple-valves, at least with two of them. Multiple actions of valves may induce very large or low pressure waves due to superposition of the waves [11]; therefore, engineers try to avoid it. However, there are reports on the usage of single or even multiple-check valves to attenuate column separation effects [12] and [13]. Recent investigations show that closure of two end valves may produce less severe column separation induced pressure fluctuations than the classical case with the downstream end single valve closure only [14]. In addition, different positions of the valves [15] and their controlled action (water hammer interferometer) [16] may attenuate pressure oscillations significantly.

The paper starts with mathematical tools for water hammer, transient cavitation and unsteady friction including boundary conditions and continues with the description of the experimental setup. In the second part of the paper, water hammer and column separation results from two valve closure experimental runs are compared with computed results. The paper concludes with a theoretical analysis of pressure wave fronts travelling along the pipeline for two end valve closure cases that include the effects of skin friction and transient cavitation.

\section{THEORETICAL MODELLING}

A simplified version of the continuity and momentum equations, neglecting the convective terms, is used to describe unsteady pipe liquid flow [1]:

$$
\begin{gathered}
\frac{\partial Q}{\partial t}+g A \frac{\partial H}{\partial x}+R Q|Q|=0, \\
a^{2} \frac{\partial Q}{\partial x}+g A \frac{\partial H}{\partial t}=0,
\end{gathered}
$$

where unknown variables are piezometric head $H$ and discharge $Q$; friction coefficient is defined as $R=f(2 D A)$.

Solving Eqs. (1) and (2) numerically with the method of characteristics (MOC) gives the following compatibility equations:

$$
\begin{aligned}
& \frac{d Q}{d t}+\frac{g A}{a} \frac{d H}{d t}+R Q|Q|=0 \\
& \frac{d Q}{d t}-\frac{g A}{a} \frac{d H}{d t}+R Q|Q|=0 .
\end{aligned}
$$

Eqs. (3) and (4) are valid along the characteristic lines $d x / d t= \pm a$ (Fig. 1).

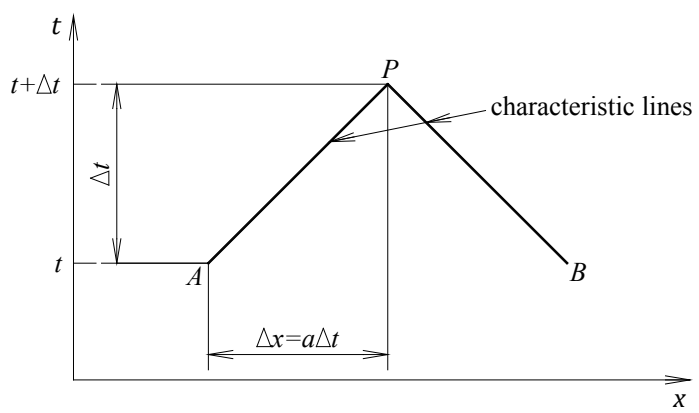

Fig. 1. Characteristic lines in $x$-t plane

It is assumed that the head, $H$, and discharge, $Q$ at time $t$ are known. These may be either initially known (i.e., at $t_{0}=0$, initial conditions), or they were calculated during the previous time step. It is necessary to compute the unknown values of $H$ and $Q$ at time $t+\Delta t$. Referring to Fig. 1, for known values of $Q$ and $H$ at points A and B it is necessary to determine their values at point P. Numerically solving Eqs. (3) and (4) along the lines AP and BP leads to [1]:

$$
\begin{aligned}
& H_{P}=C_{P}-B_{P}\left(Q_{u}\right)_{P}, \\
& H_{P}=C_{M}-B_{M}\left(Q_{d}\right)_{P},
\end{aligned}
$$

where:

$$
\begin{aligned}
& C_{P}=H_{A}-B\left(Q_{d}\right)_{A}, \\
& B_{P}=B-R\left|\left(Q_{d}\right)_{A}\right|, \\
& C_{M}=H_{C}-B\left(Q_{u}\right)_{B}, \\
& B_{M}=B+R\left|\left(Q_{u}\right)_{B}\right|,
\end{aligned}
$$

where $B=a / g A$ is the pipeline characteristic impedance which depends upon the pipe properties. 
Eq. (5) is referred as the positive characteristic equation and Eq. (6) as the negative characteristic equation [1].

\subsection{Boundary Conditions}

Boundary conditions describe relationships that define the discharge or head at a boundary, or a relationship between the head and discharge at the boundary. At the downstream end of the small-scale pipeline apparatus (Fig. 2), $x=L$, combining equations for the discharge through the ball valve $\mathrm{V} 3 / 3 \mathrm{H}$, $\boldsymbol{Q}_{\boldsymbol{P}}=\boldsymbol{C}_{\boldsymbol{b} v} \sqrt{\Delta \boldsymbol{H}_{\boldsymbol{b} v}}$ and the needle valve $\mathrm{V} 3 / 3 \mathrm{C}$, $\boldsymbol{Q}_{\boldsymbol{P}}=\boldsymbol{C}_{n v} \sqrt{\Delta \boldsymbol{H}_{n v}}$, and the positive characteristic equation, Eq. (5) gives:

$$
\begin{gathered}
Q_{P}=\frac{2 C_{C}}{C_{b}+\sqrt{C_{b}^{2}+4 C_{C}}} \text { if } C_{b}>0, \\
Q_{P}=\frac{1}{2}\left(-C_{b}+\sqrt{C_{b}^{2}+4 C_{C}}\right) \text { if } C_{b}<0,
\end{gathered}
$$

where:

$$
C_{b}=\frac{C_{n v}^{2} C_{b v}^{2} B_{P}}{C_{n v}^{2}+C_{b v}{ }^{2}}, \quad C_{c}=\frac{C_{n v}^{2} C_{b v}^{2} C_{P}}{C_{n v}^{2}+C_{b v}^{2}} .
$$

The boundary condition at the upstream end, $x=0$, is defined by combining expressions for the discharge through the ball valve V0/3U (Fig. 2) and the negative characteristic equation, Eq. (6). Taking into account a constant pressure head in the high-pressurized tank, a quadratic equation is obtained, which roots are Eqs. (11) and (12) with:

$$
C_{b}=C_{b v}^{2} B_{M}, \quad C_{c}=C_{b v}^{2}\left(C_{M}-H_{r e s}\right) .
$$

\subsection{Discrete Gas Cavity Model}

Up to date, several mathematical and numerical models for modeling of vaporous and gaseous cavitation in pipelines have been developed. The discrete gas cavity model (DGCM) [2] is used in this paper. The DGCM can successfully simulate vaporous cavitation if the amount of a free gas in the liquid is small (gas void fraction $\alpha_{g} \leq 10^{-7}$ ) [2], [4]. The model allows gas and vapour cavities to form at all computational sections in the MOC grid. A liquid phase with a constant wave speed $a$ is assumed to occupy the reaches connecting the computational sections. A discrete gas cavity is described by two water hammer compatibility equations (Eqs. (5) and (6)), the continuity equation for the cavity volume:

$$
\frac{d \forall_{g}}{d t}=Q_{\text {out }}-Q_{\text {in }}
$$

and the ideal gas equation with the assumption of isothermal behaviour of the free gas [2]:

$$
\forall_{g}=\alpha_{g} \forall\left(\frac{p_{0}^{*}}{p_{g}^{*}}\right) .
$$

A detailed description of the DGCM and its numerical solution is given in [2]. The MOC based DGCM algorithm in this paper incorporates an improved computationally effective [17] Zielke's convolution-based (with quasi-2-D weighting function) unsteady friction model [18]. Zielke's weighting function for transient laminar flow [18] and Vardy-Brown weighting functions for transient turbulent flow [19] to [21] are used in the numerical simulations.

\section{EXPERIMENTAL SETUP}

Experimental research was conducted in a small-scale pipeline apparatus for investigation of water hammer events including column separation and fluid-structure interaction [22].

The apparatus is comprised of a horizontal pipeline that connects the upstream end highpressurized tank to the outflow tank (steel pipe of total length $L=55.37 \mathrm{~m}$; internal diameter $D=18 \mathrm{~mm}$; pipe wall thickness $e=2 \mathrm{~mm}$; maximum allowable pressure in the pipeline $p_{\max , \text { all }}=25 \mathrm{MPa}$ ) - see Fig. 2. Four valve units are positioned along the pipeline including the end points. The valve units at the upstream end tank (position 0/3) and at the two equidistant positions along the pipeline (positions $1 / 3$ and $2 / 3$ ) consist of two hand-operated ball valves (valves $\mathrm{V} i / 3 \mathrm{U}$ and $\mathrm{V} i / 3 \mathrm{D} ; i=0,1,2$ ) that are connected to the intermediate pressure transducer block. The air pressure in the upstream end tank can be adjusted up to $800 \mathrm{kPa}$. The pressure in the tank is kept constant during each experimental run by using a high-precision fast-acting air pressure regulator (precision class: $0.2 \%$ ) in the compressed air supply line. Four dynamic high-frequency pressure transducers are positioned within the valve units along the pipeline including the end points (see Fig. 2). Pressures $p_{0 / 3}, p_{1 / 3}, p_{2 / 3}$ and $p_{3 / 3}$ are measured by Dytran 2300V4 high-frequency piezoelectric absolute pressure transducers (pressure range: from $0 \mathrm{MPa}$ to 6.9 MPa; resonant frequency: $500 \mathrm{kHz}$; acceleration compensated; discharge time constant: 10 seconds (fixed)). The datum level for all pressures measured in the pipeline and at the tank is at the top of the 
horizontal steel pipe (elevation $0 \mathrm{~m}$ in Fig. 2). The water temperature is continuously monitored by the thermometer installed in the outflow tank. The water hammer wave speed was determined as $a=1340 \mathrm{~m} / \mathrm{s}$ $\pm 10 \mathrm{~m} / \mathrm{s}$ [26]. The fast closing electro-pneumatically operated ball valve $(\mathrm{V} 3 / 3 \mathrm{P})$ is controlled with filtered compressed air which is supplied through a plastic pipeline from the pressure regulator, in which the pressure is independent from the rest of the system. The transient event can be triggered by fast closing or opening of the downstream end valve, using either the $\mathrm{V} 3 / 3 \mathrm{P}$ or the $\mathrm{V} 3 / 3 \mathrm{H}$. Both valves are equipped with a fast-response displacement sensor (measurement range: $0^{\circ}$ to $90^{\circ}$, frequency response: $>10 \mathrm{kHz}$ ) which measures the change of the valve angle $(\alpha)$ during its closing or opening. In addition, transients can be induced by closing or opening hand-operated valves along the pipeline (valves $\mathrm{Vi} / 3 \mathrm{U}$ and $\mathrm{Vi} / 3 \mathrm{D}$; $i=0,1,2$ ). At the upstream end high-pressurized tank and at the downstream end of the pipeline, two strain-gauge pressure transducers $\left(p_{0 / 3 \text {-sg }}\right.$ and $p_{3 / 3 \text {-sg; }}$; pressure range: from $0 \mathrm{MPa}$ to $1 \mathrm{MPa}$, uncertainty: $\pm 0.5 \%$ ) are installed. These transducers are used for the evaluation of the initial conditions in the system. The needle valve (V3/3C) is used for adjustment of the initial pipe discharge. The initial discharge (velocities larger than $0.3 \mathrm{~m} / \mathrm{s}$ ) is measured by the electromagnetic flow meter (uncertainty: $\pm 0.2 \%$ ). All measured data are collected by the data acquisition system (sample rate: up to $100 \mathrm{kHz}$ ) that is connected to a PC. In the cases presented in the paper, transients were induced by 'simultaneous' closure of 1) the hand-operated ball valve at the downstream end of the pipeline and 2) the hand-operated ball valve at the upstream end $(\mathrm{V} 3 / 3 \mathrm{H}+\mathrm{V} 0 / 3 \mathrm{U})$. The pressure in the upstream tank was $400 \mathrm{kPa}$ and initial pipe velocities were $0.3 \mathrm{~m} / \mathrm{s}$ and $2.12 \mathrm{~m} / \mathrm{s}$. This apparatus has been classified as an unsteady friction dominated apparatus [22] because the Ghidaoui's parameter [23] is close to 1 . The relative importance of unsteady friction for the two case studies is indicated by the Duan's parameter [24]: $I=0.007$ for $V_{0}=0.30 \mathrm{~m} / \mathrm{s}$ and $I=0.05$ for $V_{0}=2.12 \mathrm{~m} / \mathrm{s}$. The effects of unsteady friction for rapid transients are important when $I<0.1$.

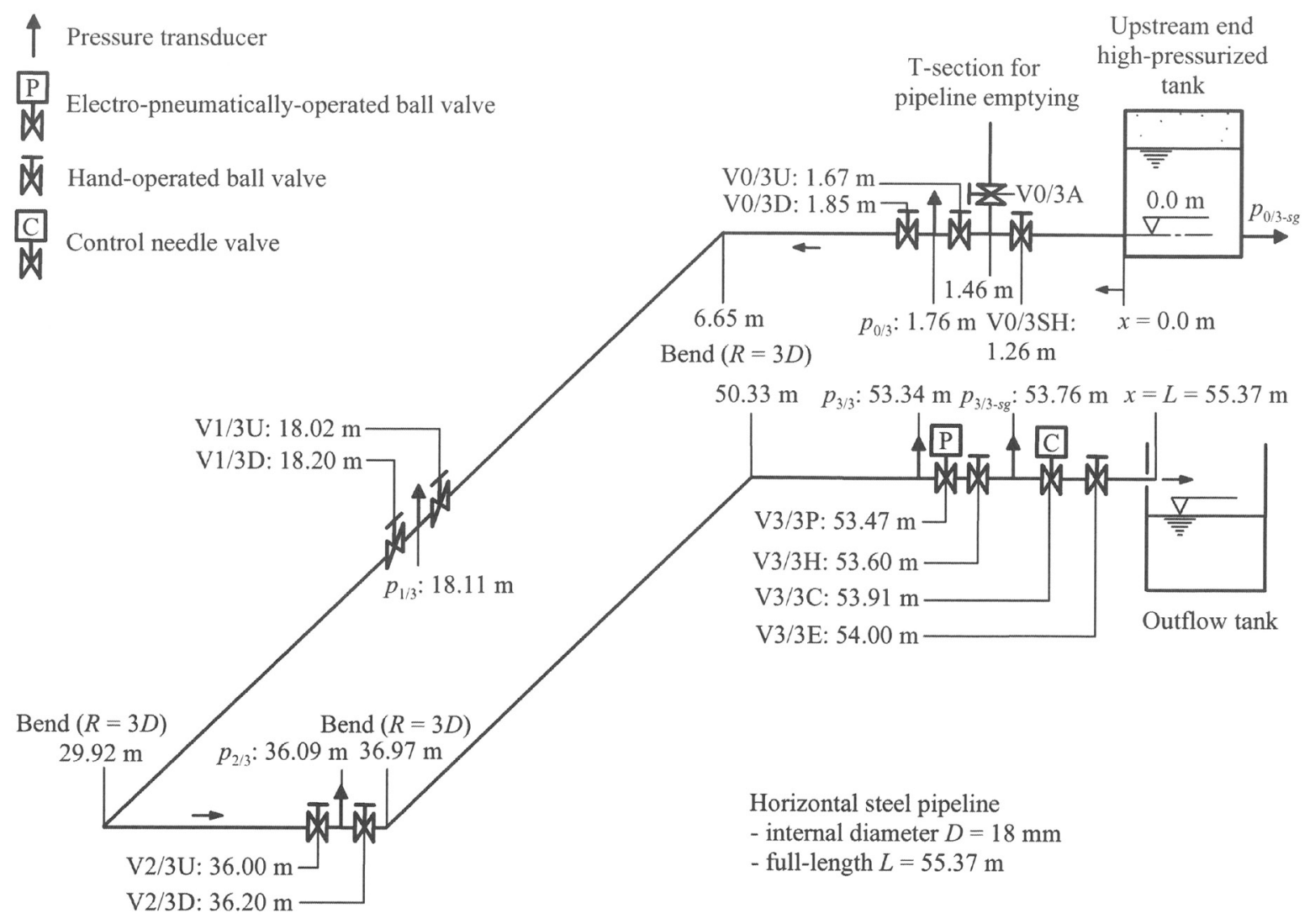

Fig. 2. Layout of small-scale pipeline apparatus 


\section{EXPERIMENTAL AND NUMERICAL RESULTS}

A number of experiments have been performed in the laboratory pipe system (Fig. 2) for better understanding of unsteady flow phenomena caused by the closure of two valves. The valve closures were induced 'simultaneously' as much as possible by using valve $\mathrm{V} 3 / 3 \mathrm{H}$ at the downstream end of the pipeline and valve V0/3U at the upstream end. Results from two distinct experimental runs are presented and compared with calculated results in this section: 1) water hammer case and 2) column separation case. Transients were induced first by a fast closure of the downstream end valve $\mathrm{V} 3 / 3 \mathrm{H}$ and second by a delayed fast closure of the upstream end valve $\mathrm{V} 0 / 3 \mathrm{U}$. The sampling frequency for each continuously measured quantity was $f_{s}=3,000 \mathrm{~Hz}$.

\subsection{Water Hammer Case}

Fig. 3 presents measured and computed pressure head traces in the laboratory pipeline apparatus $\left(H_{3 / 3}, H_{2 / 3}\right.$, $H_{1 / 3}$ and $H_{0 / 3}$ ) for the rapid closure of the two valves for the initial flow velocity $V_{0}=0.3 \mathrm{~m} / \mathrm{s}$; the effective valve closure times were much less than the wave reflection time $2 L / a=0.08 \mathrm{~s}$. This experimental run represents the water hammer case (pressure head is above the vapour pressure head at all times).

The fast closure of the downstream end valve $(\mathrm{V} 3 / 3 \mathrm{H})$ produces the classical Joukowsky pressure head rise $\Delta H_{\max }=41.3 \mathrm{~m}$. The second delayed fast closure of the upstream end valve $(\mathrm{V} 0 / 3 \mathrm{U})$ produces a pressure head rise at this valve of practically the same magnitude. The time delay between the two valve closures is $0.036 \mathrm{~s}$ and the time difference between the two measured maximum heads is $0.03 \mathrm{~s}$ (due to different valve closure times of $40 \mathrm{~ms}$ and $34 \mathrm{~ms}$, respectively). The maximum head due to the closure of $\mathrm{V} 0 / 3 \mathrm{U}$ occurs within the second water hammer time period $(L / a<t<2 L / a)$. The maximum measured head $H_{\max }=83.0 \mathrm{~m}$ occurs at the downstream end valve as a short duration pressure pulse superimposed on the third bulk pressure pulse and it is slightly larger than first bulk head of $80.0 \mathrm{~m}$. Overall, there is good agreement between measured and computed results.

\subsection{Column Separation Case}

Fig. 4 shows measured and computed head traces in the pipeline apparatus $\left(H_{3 / 3}, H_{2 / 3}, H_{1 / 3}\right.$ and $\left.H_{0 / 3}\right)$ for the fast closure of the two valves for the initial flow velocity $V_{0}=2.12 \mathrm{~m} / \mathrm{s}$. In this case column separation
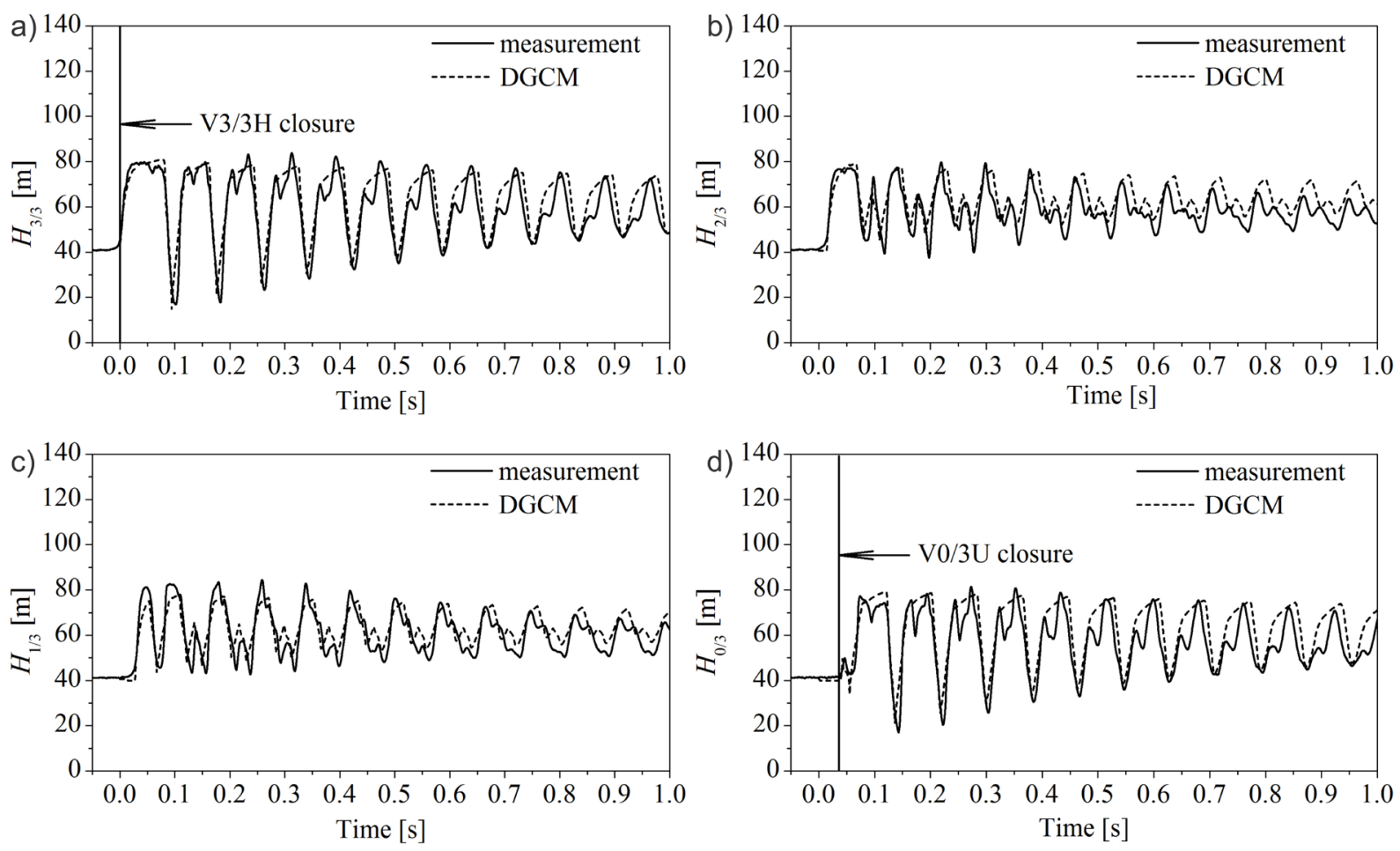

Fig. 3. Comparison of measured and calculated heads at two end valves; a) $H_{3 / 3}$ and d) $H_{0 / 3}$ and along the pipeline; b) $H_{2 / 3}$ and c) $H_{1 / 3}$; $V_{0}=0.3 \mathrm{~m} / \mathrm{s} ; p_{\text {res }}=400 \mathrm{kPa}$; 'Simultaneous' closure of the valves $\mathrm{V} 3 / 3 \mathrm{H}$ and $\mathrm{V} 0 / 3 \mathrm{U}$ (slight delay) 

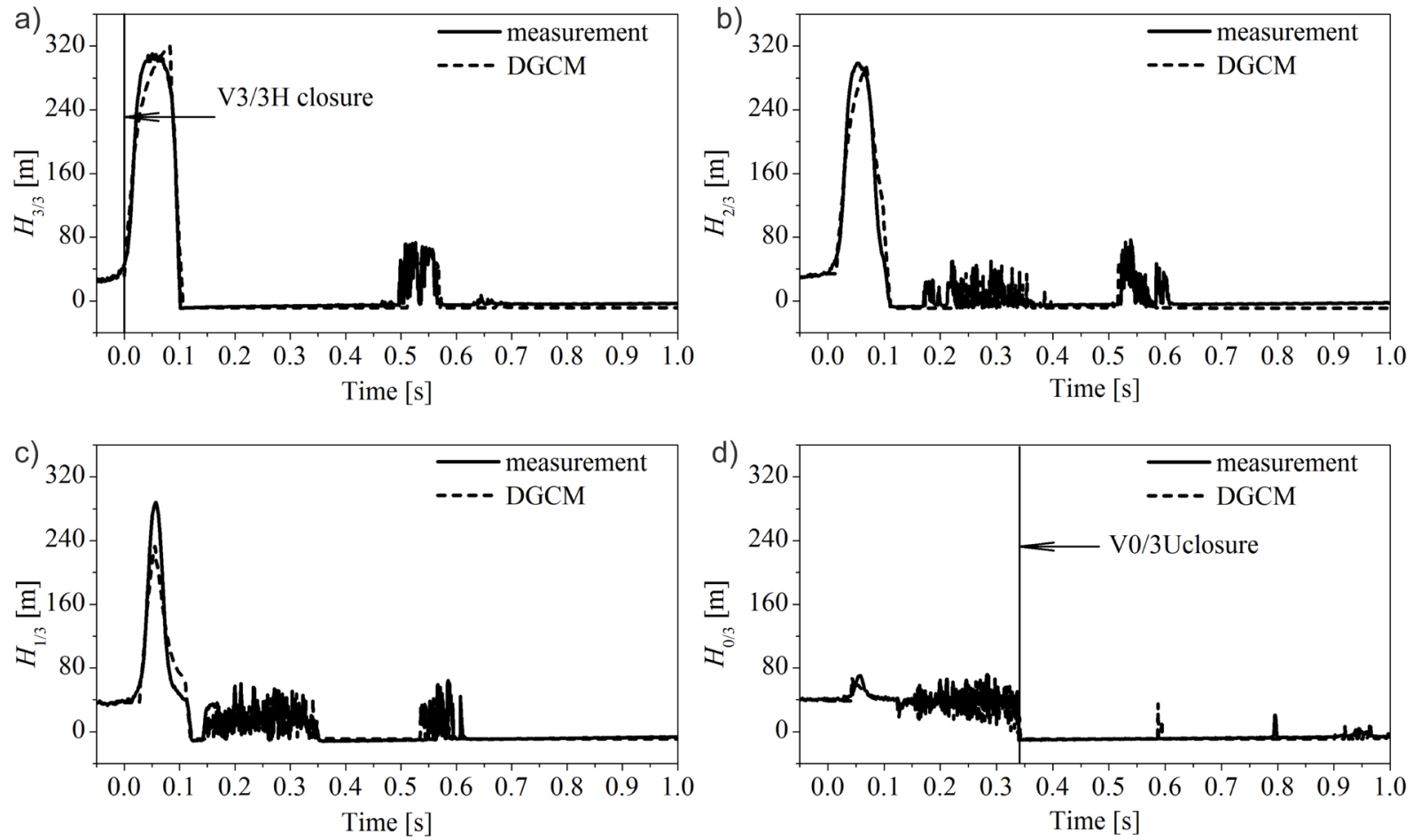

Fig. 4. Comparison of measured and calculated heads at two end valves; a) $H_{3 / 3}$ and d) $H_{0 / 3}$ and along the pipeline; b) $H_{2 / 3}$ and c) $H_{1 / 3}$; $V_{0}=2.12 \mathrm{~m} / \mathrm{s} ; p_{\text {res }}=400 \mathrm{kPa}$; 'Simultaneous' closure of the valves $\mathrm{V} 3 / 3 \mathrm{H}$ and $\mathrm{V} 0 / 3 \mathrm{U}$ (delay)

occurs in the system. Again the valve closure times were less than the wave reflection time $2 L / a=0.08$ seconds (V3/3H: $70 \mathrm{~ms}$ and V0/3U: $65 \mathrm{~ms}$ ).

The column separation case produces water hammer with column separation including large cavities and extended regions of distributed vaporous cavitation along the pipeline. The initial fast closure of the downstream end valve $(\mathrm{V} 3 / 3 \mathrm{H})$ produces the classical Joukowsky pressure head rise $\Delta H_{\max }=277.9$ $\mathrm{m}$. The second delayed fast closure of the upstream end valve $(\mathrm{V} 0 / 3 \mathrm{U})$ produces a pressure head drop from the reservoir head to the vapour pressure head of $-9.8 \mathrm{~m}$. The time delay between the two end valve closures is $0.34 \mathrm{~s}$. At the time of the pressure drop at $\mathrm{V} 0 / 3 \mathrm{U}$ the water flows from the reservoir towards the downstream end. The pressure heads along the pipeline remain practically constant at the vapour pressure head for a longer period. The first fast closure of the downstream end valve $(\mathrm{V} 3 / 3 \mathrm{H})$ produces the maximum pressure head $H_{\max }=H_{0}+\Delta H_{\max }=310.3 \mathrm{~m}$ in the system. The results obtained using the DGCM give pressure histories that are in good agreement with the experimental results. Reopening of one or both valves at selected time(s) after the closing periods is subject of the authors' future work.

\section{THEORETICAL ANALYSIS OF PRESSURE WAVES IN FRICTIONLESS PIPE AND FRICTION DOMINATED PIPE (WATER HAMMER CASE)}

Fig. 5 shows the responses of the reservoir-pipelinevalve and reservoir-valve-pipeline-valve system of Fig. 2 considering two theoretical cases: 1) the first one is an ideal frictionless system without cavitation and 2) the second one is system without cavitation but with consideration of unsteady skin friction (water hammer case). The steady flow is stopped 1) by instantaneous downstream end valve closure and 2) by instantaneous simultaneous or sequential (delayed) two end valve closures. The initial flow conditions are the same as for the water hammer case in Section 3.1 with the initial flow velocity $V_{0}=0.30 \mathrm{~m} / \mathrm{s}$. Figs. $5 \mathrm{a}$ and $b$ show the case of $\mathrm{V} 3 / 3 \mathrm{H}$ valve closure (V0/3U stays open). The unsteady friction obviously produces attenuation of pressure waves and also rounds pressure pulses. Comparison of quasi-steady and unsteady friction effects has been previously shown in [11]. Timing of the pressure waves is practically unaffected by friction effects. The pressure at the position $x / L=$ 0 has a constant value equal to the reservoir pressure. Effects of unsteady friction show similar behavior for the case of the simultaneous closure of the two valves 
Theoretical case without friction and cavitation

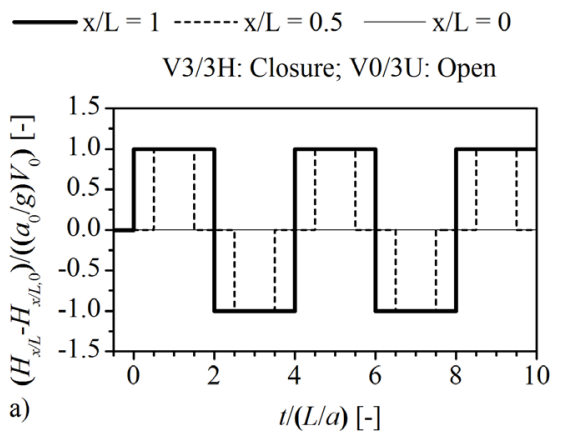

V3/3H \& V0/3U: Simultaneous Closure

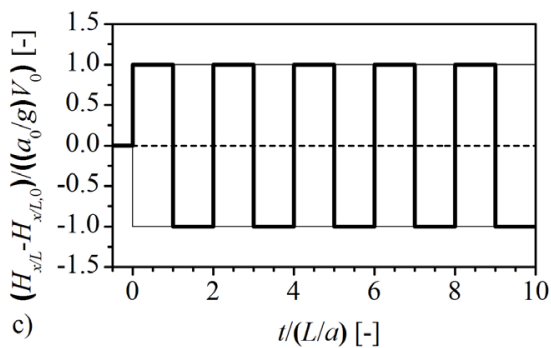

V3/3H: Closure; V0/3U: L/a Delayed Closure

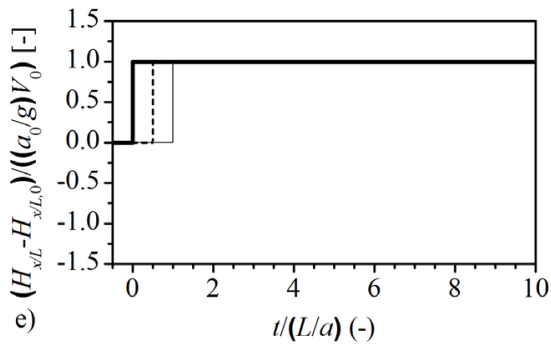

V3/3H: Closure; V0/3U: 1.5 L/a Delayed Closure

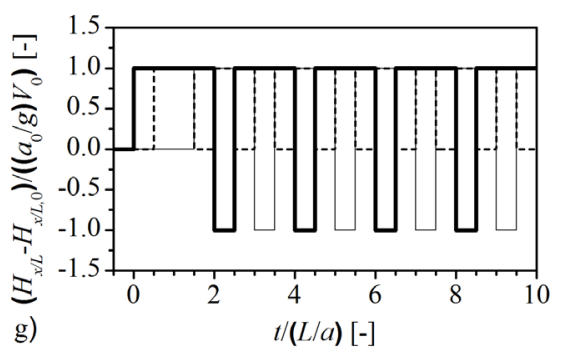

V3/3H: Closure; V0/3U: 4 L/a Delayed Closure

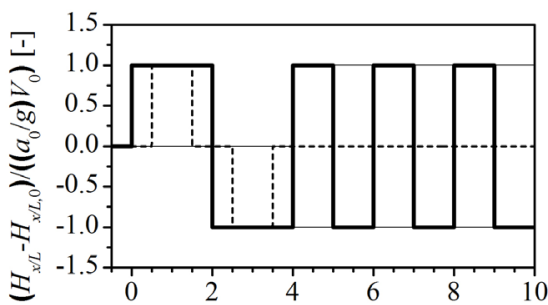

i)

$t /(L / a)[-]$
Theoretical case with friction and without cavitation

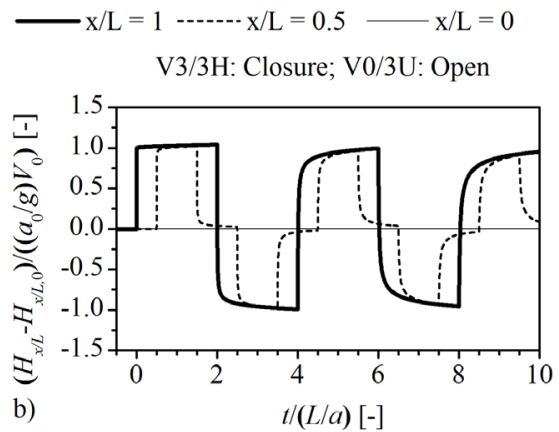

V3/3H \& V0/3U: Simultaneous Closure

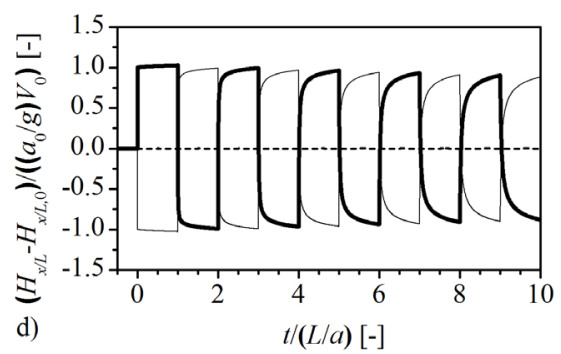

V3/3H: Closure; V0/3U: L/a Delayed Closure

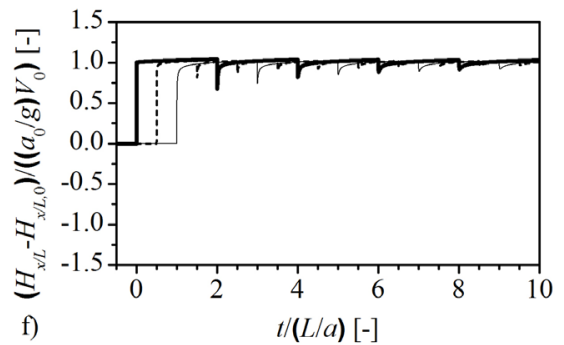

V3/3H: Closure; V0/3U: 1.5 L/a Delayed Closure

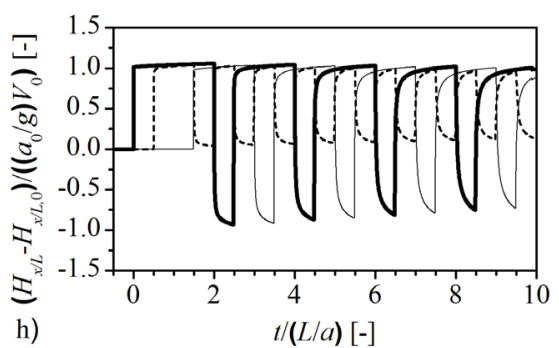

V3/3H: Closure; V0/3U: 4 L/a Delayed Closure

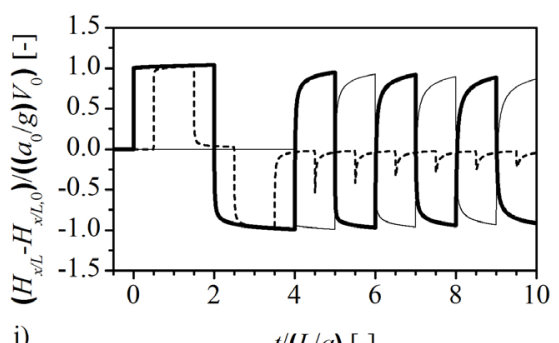

j)

Fig. 5. Comparison of theoretical dimensionless heads (without and with friction) at the end valves $\left(x / L=1\right.$ and 0 ) and at the midpoint $(x / L=0.5) ; V_{0}=0.3 \mathrm{~m} / \mathrm{s} ; p_{\text {res }}=400 \mathrm{kPa}$ 
(Figs. $5 \mathrm{c}$ and $5 \mathrm{~d}$ ). In this case the pressure at $x / L=$ 0.5 is constant at all times and equal to the reservoir pressure. Pressure variations at the two valves occur with a period of $2 L / a$. The case when $\mathrm{V} 0 / 3 \mathrm{U}$ is closed instantaneously at time $L / a$ after $\mathrm{V} 3 / 3 \mathrm{H}$ closure is shown in Figs. 5e and 5f. After V3/3H instantaneous closure a high-pressure wave is formed that travels towards $\mathrm{V} 0 / 3 \mathrm{U}$. At the time $L / a$ this high pressure wave arrives at the reservoir and at this instant $\mathrm{V} 0 / 3 \mathrm{U}$ is closed resulting in "trapped" constant high pressure in the pipeline (Fig. 5e). Due to frictional effects some small pressure drops are detected in the pipeline after V0/3U closure (Fig. 5f) which attenuate rapidly. The liquid in the pipeline now is at standstill condition. Delayed closure of valve $\mathrm{V} 0 / 3 \mathrm{U}$ at the time $1.5 \mathrm{~L} / \mathrm{a}$ after closure of $\mathrm{V} 3 / 3 \mathrm{H}$ is shown in Figs. $5 \mathrm{~g}$ and $\mathrm{h}$. In this case the pressure wave, formed by $\mathrm{V} 3 / 3 \mathrm{H}$ closure, travels towards the upstream end reservoir, reflects back and passes the midpoint of the pipeline when $\mathrm{V} 0 / 3 \mathrm{U}$ instantaneous closure occurs at the time $1.5 \mathrm{~L} / \mathrm{a}$. At this moment the liquid is flowing towards the reservoir and closure of the $\mathrm{V} 0 / 3 \mathrm{U}$ causes the occurrence of the second positive pressure wave that travels in the same direction as the first pressure wave but with a delay of $0.5 \mathrm{~L} / \mathrm{a}$. At the midpoint the pressure changes from initial to high pressure with the period $0.5 \mathrm{~L} / \mathrm{a}$. The unsteady friction effects are similar to the previous cases.

The second valve closure with time delay $4 L / a$ is the case that is a combination of the classical water hammer case $(0 \leq t \leq 4 L / a)$ and the simultaneous two valve closure case $(t>4 L / a)$ (Fig. 5i). An interesting situation is at $x / L=0.5$ where some negative pressure spikes can be noticed in the case with friction (Fig. $5 j$ ). This can be explained as follows. There are two pressure waves, first is the pressure wave initiated by the first valve closure $(\mathrm{V} 3 / 3 \mathrm{H})$ and the second pressure wave initiated by closure of $\mathrm{V} 0 / 3 \mathrm{U}$ at $t=4 \mathrm{~L} / \mathrm{a}$. When the second wave is generated, the first pressure wave has already been attenuated due to friction. When they meet at $x / L=0.5$ the second pressure wave has a larger value than the first pressure wave and after their interference a short-duration pressure drop occurs. After a certain amount of time, due to friction, this pressure spike disappears. In the case without friction (Fig. 5i) both pressure waves have the same value when they meet; therefore, their superposition just cancels each other. This comprehensive theoretical analysis of unsteady friction effects in the two valve closure case is new in the literature.

\section{THEORETICAL ANALYSIS OF PRESSURE WAVES IN FRICTIONLESS PIPE AND FRICTION DOMINATED PIPE INCLUDING EFFECTS OF CAVITATION (COLUMN SEPARATION CASE)}

Far more complex is the case with transient cavitating pipe flow (column separation). Comparison of theoretical dimensionless heads without and with consideration of unsteady friction is shown in Fig. 6. As for the water hammer case, (Section 4), the steady flow is stopped 1) by instantaneous downstream end valve closure and 2) by instantaneous simultaneous or sequential (delayed) closure of two end valves. The initial flow conditions are the same as for the column separation case in Section 3.2 with the initial flow velocity $V_{0}=2.12 \mathrm{~m} / \mathrm{s}$.

The effects of cavitation and unsteady friction for the case of $\mathrm{V} 3 / 3 \mathrm{H}$ closure ( $\mathrm{V} 0 / 3 \mathrm{U}$ stays open) are depicted in Figs. 6a and b. It is obvious that cavitation limits the minimum pressure head to the liquid vapour pressure head at the position $x / L=1$ where cavitation starts at $2 L / a$. The pressure head at $x / L=0$ stays at the reservoir pressure head at all times. The pressure head at $x / L=0.5$, after cavitation starts at the time $2.5 \mathrm{~L} / \mathrm{a}$, fluctuates between the initial and the vapour pressure head with a period of $L / a$. No doubts that cavitation has a predominant effect on the pressure response. For the case of the simultaneous closure of the two valves (Figs. 6c and d) the effects of cavitation play a major role again. Unsteady friction contributes to slight attenuation and timing of bulk pressure pulses. Naturally the minimum pressure heads along the pipeline are limited to the liquid vapour pressure head. As described previously in Section 4, instantaneous $\mathrm{V} 0 / 3 \mathrm{U}$ closure at time $L / a$ after $\mathrm{V} 3 / 3 \mathrm{H}$ closure results in a constant high pressure along the pipeline. Therefore, cavitation does not appear in this case and this is clearly depicted in Figs. 6e and f. System response for the case of $1.5 \mathrm{~L} / \mathrm{a}$ delayed $\mathrm{V} 0 / 3 \mathrm{U}$ closure after $\mathrm{V} 3 / 3 \mathrm{H}$ is closed is even more profound (Figs. $6 \mathrm{~g}$ and $\mathrm{h}$ ). The pressure response at $x / L=1$ and $x / L=$ 0 is similar with a delay of $L / a$ to each other. At $x / L$ $=0.5$ (midpoint of the pipeline) cavitation occurs at time $3 \mathrm{~L} / \mathrm{a}$ and lasts for $0.5 \mathrm{~L} / \mathrm{a}$. After that no cavitation exists at the midpoint. The second valve closure with a time delay of $4 L / a$ produces longer periods of cavitation existence along the pipeline (Figs. 6i and j). At $x / L=1$ cavitation starts at time $2 L / a$ and lasts until $7.5 L / a$. At $x / L=0$ cavitation also occurs at $2 L / a$ after $\mathrm{V} 0 / 3 \mathrm{U}$ is closed and exists for a longer period. Similar behaviour can be observed at the midpoint of the pipeline too. Finally, the two valve closure case with cavitation exhibits its profound effect on pressure 
Theoretical case without friction and with cavitation

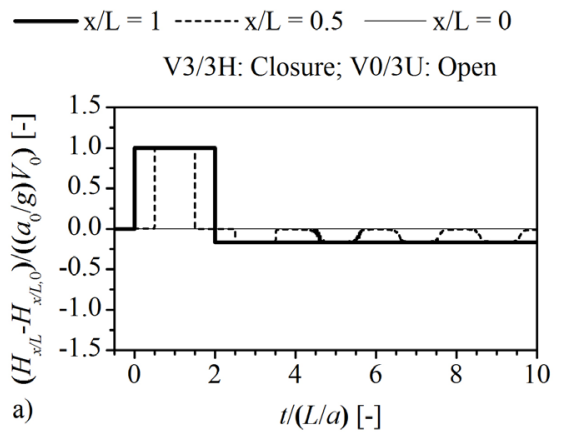

V3/3H \& V0/3U: Simultaneous Closure

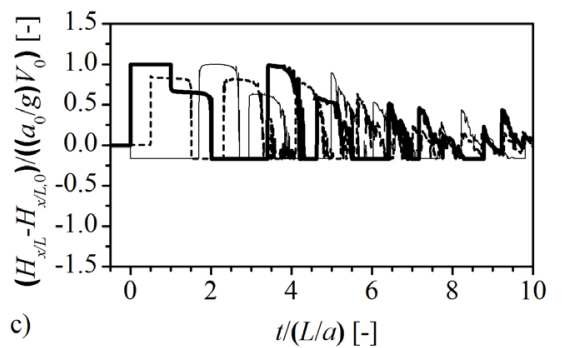

V3/3H: Closure; V0/3U: L/a Delayed Closure

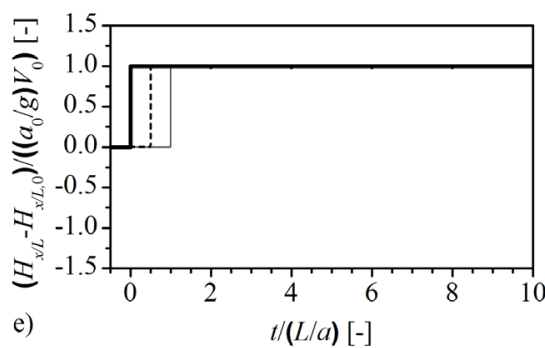

V3/3H: Closure; V0/3U: 1.5 L/a Delayed Closure

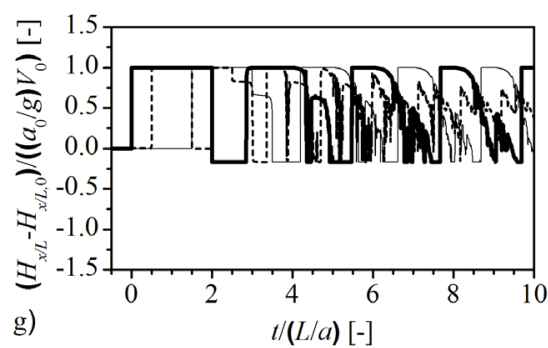

V3/3H: Closure; V0/3U: 4 L/a Delayed Closure

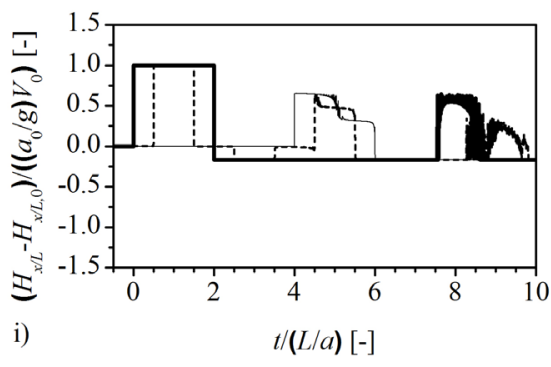

Theoretical case with friction and with cavitation

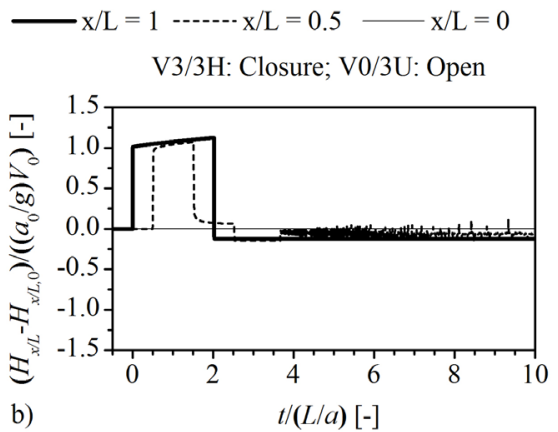

V3/3H \& V0/3U: Simultaneous Closure

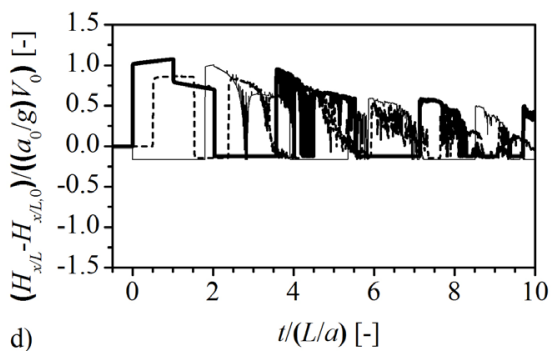

V3/3H: Closure; V0/3U: L/a Delayed Closure

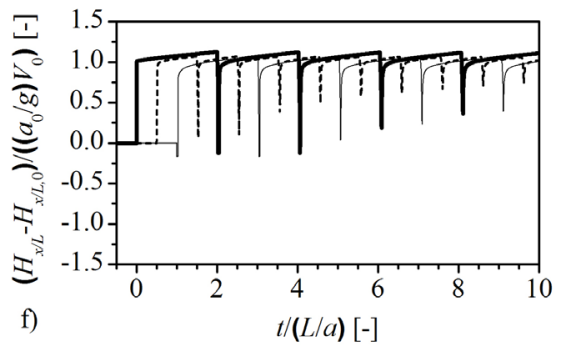

V3/3H: Closure; V0/3U: 1.5 L/a Delayed Closure

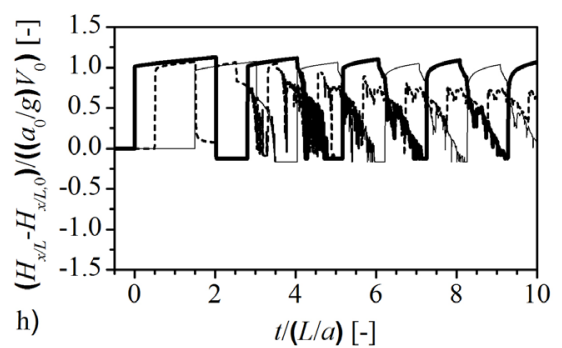

V3/3H: Closure; V0/3U: 4 L/a Delayed Closure

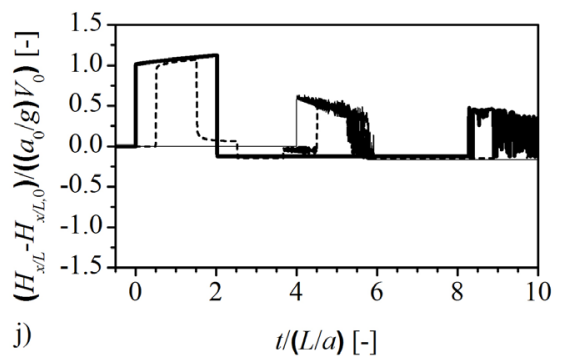

Fig. 6. Comparison of theoretical dimensionless heads (without and with friction) at the end valves $(x / L=1$ and 0$)$ and at the midpoint $(x / L=0.5) ; V_{0}=2.12 \mathrm{~m} / \mathrm{s} ; p_{\text {res }}=400 \mathrm{kPa}$ 
response while unsteady friction only slightly affects the amplitude, shape and timing of the pressure pulses.

\section{CONCLUSIONS}

Water hammer and column separation effects triggered by simultaneous and sequential (delayed) closure of two end valves have been investigated in a laboratory pipeline apparatus. A numerical discrete gas cavity model (DGCM) with inclusion of the convolutionbased unsteady friction term has been successfully validated against the investigated experimental runs including water hammer and column separation cases. Finally, a novel theoretical analysis of pressure wave fronts travelling along the pipeline triggered by simultaneous and delayed closure of the two end valves for cases without and with friction and transient cavitation has been presented. It has been shown that unsteady friction affects rounding and attenuation of pressure head pulses but has no major impact on their timing. Effects of cavitation on pressure histories are far more profound because they include liquid rupture, waves and shocks. Depending on the second valve closure delay cavitation may be a long or short lasting event. In some cases (V0/3U, $L / a$ delayed closure) cavitation does not occur at all.

In the near future, the authors are planning to improve the experimental setup by installing one additional fast closing electro-pneumatically operated ball valve instead of $\mathrm{V} 0 / 3 \mathrm{U}$ and a new PLC (programmable logic controller). In this way simultaneous and controlled sequential closure of the two electro-pneumatically operated ball valves will be possible thus enabling further experimental, numerical and theoretical investigations in the relatively new field of controlled multiple valve actions in pipelines.

\section{NOMENCLATURES}

A cross-sectional area, $\left[\mathrm{m}^{2}\right]$

$a$ wave speed, $[\mathrm{m} / \mathrm{s}$ ]

$B$ pipeline characteristic impedance, $\left[\mathrm{m}^{2} \mathrm{~s}\right]$

$B_{M}$ constant of positive characteristic equation, $\left[\mathrm{m} /\left(\mathrm{m}^{3} / \mathrm{s}\right)\right]$

$B_{P}$ constant of negative characteristic equation, $\left[\mathrm{m} /\left(\mathrm{m}^{3} / \mathrm{s}\right)\right]$

$C$ discharge coefficient, [-]

$C_{M}$ constant of positive characteristic equation, [m]

$C_{P}$ constant of negative characteristic equation, [m]

$D$ pipe internal diameter, $[\mathrm{m}]$

$E \quad$ Young's modulus of elasticity, $\left[\mathrm{N} / \mathrm{m}^{2}\right]$

$e$ pipe wall thickness, [m]

$f$ friction coefficient, [-] $f_{s} \quad$ sampling frequency, $[\mathrm{Hz}]$

$g$ gravitational acceleration, $\left[\mathrm{m} / \mathrm{s}^{2}\right]$

$H$ piezometric head (head)

I Duan's parameter, [-]

$L$ length, [m]

$N$ number of computational reaches, [-]

$p$ pressure, $\left[\mathrm{N} / \mathrm{m}^{2}\right]$

$Q$ discharge, $\left[\mathrm{m}^{3} / \mathrm{s}\right]$

$R$ friction coefficient, pipe bend radius, $\left[1 / \mathrm{m}^{3}\right],[\mathrm{m}]$

$V$ flow velocity, $[\mathrm{m} / \mathrm{s}]$

$x$ axial distance, $[\mathrm{m}]$

$\alpha \quad$ valve opening angle, $\left[{ }^{\circ}\right]$

$\alpha_{g}$ volume fraction of gas in mixture with a fluid, [-]

$\Delta H$ losses at the valve, pressure head increase, [m]

$\forall$ volume, $\left[\mathrm{m}^{3}\right]$

Subscripts:

0 initial conditions

$d$ downstream

bv ball valve

$g$ gas

in inlet

max maximum value

$n v$ needle valve

out outlet

$q$ quasi-steady

res reservoir

$u$ unsteady, upstream

\section{ACKNOWLEDGEMENTS}

The authors gratefully acknowledge the support of the Ministry of Science of Montenegro (MSM) and of the Slovenian Research Agency (ARRS) through the projects BI-ME/14-15-016 (MSM, ARRS) and L25491 (ARRS).

\section{REFERENCES}

[1] Chaudhry, M.H. (2014). Applied Hydraulic Transients. 3rd ed., Springer, New York, Dol:10.1007/978-1-4614-8538-4.

[2] Wylie, E.B., Streeter, V.L. (1993). Fluid Transients in Systems. Prentice-Hall, Englewood Cliffs.

[3] Bergant, A., Tijsseling, A.S., Vítkovský, J.P., Covas, D.I.C., Simpson, A.R., Lambert, M.F. (2008). Parameters affecting water wave attenuation, shape and timing. Part 1: Mathematical tools. Journal of Hydraulic Research, vol. 46, no. 3, p. 373-381, D0l:10.3826/jhr.2008.2848.

[4] Bergant, A., Simpson, A.R., Tijsseling, A.S. (2006). Water hammer with column separation: A historical review. Journal of Fluids and Structures, vol. 22, no. 2, p. 135-171, D0I:10.1016/j.jfluidstructs.2005.08.008.

[5] Kessal, M., Bennacer, R. (2005). A new gas release model for a homogeneous liquid gas mixture flow in pipelines. 
International Journal of Pressure Vessels and Piping, vol. 82, no. 9, p. 713-721, D0I:10.1016/j.jjpvp.2005.03.005.

[6] Vardy, A.E. (1980). Unsteady flow: fact and friction.

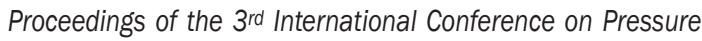
Surges, p. 15-26.

[7] Vardy, A.E., Brown, J.M.B. (2010). Evaluation of unsteady wall shear stress by Zielke's method. Journal of Hydraulic Engineering, vol. 136, no. 7, p. 453-456, D0l:10.1061/(ASCE) HY.1943-7900.0000192.

[8] Meniconi, S., Duan, H.F., Brunone, B., Ghidaoui, M.S., Lee, P.J., Ferrante, M. (2014). Further developments in rapidly decelerating turbulent flow modelling. Journal of Hydraulic Engineering, vol. 140, no. 7, p. 04014028-1-9, D0l:10.1061/ (ASCE)HY.1943-7900.0000880.

[9] Pezzinga, G., Brunone, B. (2006). Turbulence, friction and energy dissipation in transient pipe flow. Brocchini, M., Trivellato, F. (eds.), Vorticity and Turbulence Effects in Fluid Structure Interaction, WIT Press, Southampton, p. 213-236, DOI:10.2495/978-1-84564-052-1/09.

[10] He, S., Ariyaratne, C., Vardy, A.E. (2008). A computational study of wall friction and turbulence dynamics in accelerating pipe flows. Computers \& Fluids, vol. 37, no. 6, p. 674-689, D0I:10.1016/j.compfluid.2007.09.001.

[11] Bergant, A., Karadžić, U. (2015). Developments in valveinduced water-hammer experimentation in a small-scale pipeline apparatus. Proceedings of the $12^{\text {th }}$ International Conference on Pressure Surges, p. 639-652.

[12] Karney, B.W., Simpson, R.A. (2007). In-line check valves for water hammer control. Journal of Hydraulic Research, vol. 45, no. 4, p. 547-554, D0l:10.1080/00221686.2007.9521790.

[13] Dudlik, A., Schönfeld, S.B.H., Schlüter, S., Prasser, M.H. (2004). ABS-Armaturen für Rohrleitungen. Hydraulisches Bremssystem vermeidet Druckstöße und Kavitationschläge. P\&A Kompendium 2004, p. 203-205.

[14] Bergant, A., Karadžić, U., Tijsseling, A. (2017). Developments in multiple-valve pipeline column separation control. IOP Conf.
Series: Journal of Physics: Conference Series, vol. 813, no. 1, DOI:10.1088/1742-6596/813/1/012015.

[15] Ikeo, S., Kobori, T. (1975). Water hammer caused by valve stroking in a pipe line with two valves. Bulletin of JSME, vol. 18, no. 124, p. 1151-1157, D0l:10.1299/jsme1958.18.1151.

[16] Bergant, A. (2016). Principles of water hammer interferometer. Journal of Energy Technology, vol. 9, no. 4, p. 11-20.

[17] Vítkovský, J.P., Stephens, M., Bergant, A., Lambert, M.F., Simpson, A.R. (2004). Efficient and accurate calculation of Zielke and Vardy-Brown unsteady friction in pipe transients. Proceedings of the $9^{\text {th }}$ International Conference on Pressure Surges, p. 405-419.

[18] Zielke, W. (1968). Frequency-dependent friction in transient pipe flow. Journal of Basic Engineering, vol. 90, no. 1, p. 109115, DOl:10.1115/1.3605049.

[19] Vardy, A.E., Brown, E.B. (2003). Transient turbulent friction in smooth pipe flows. Journal of Sound and Vibration, vol. 259, no. 5, p. 1011-1036, D0l:10.1006/jsvi.2002.5160.

[20] Vardy, A.E., Brown, J.M.B. (2004). Transient turbulent friction in fully rough pipe flows. Journal of Sound and Vibration, vol. 270, no. 1-2, p. 233-257, DOl:10.1016/S0022-460X(03)00492-9.

[21] Vardy, A.E., Brown, J.M.B., He, S., Ariyaratne, C., Gorji, S. (2015). Applicability of frozen-viscosity models of unsteady wall shear stress. Journal of Hydraulic Engineering, vol. 141, no. 1, p. 1-13, D0l:10.1061/(ASCE)HY.1943-7900.0000930.

[22] Karadžić, U., Bulatović, V., Bergant, A. (2014). Valve-induced water hammer and column separation in pipeline apparatus. Strojniški vestnik - Journal of Mechanical Engineering, vol. 60, no. 11, p. 742-754, D0l:10.5545/sv-jme.2014.1882.

[23] Ghidaoui, M.S, Mansour, S.G.S., Zhao, M. (2002). Applicability of quasisteady and axisymmetric turbulence models in water hammer. Journal of Hydraulic Engineering, vol. 128, no. 10, p. 917-924, DOI:10.1061/(ASCE)0733-9429(2002)128:10(917).

[24] Duan, H.-F., Ghidaoui, M.S, Lee, P.J., Tung, Y.K. (2012). Relevance of unsteady friction to pipe size and length in pipe fluid transients. Journal of Hydraulic Engineering, vol. 138, no. 2, p. 154-166, DOI:10.1061/(ASCE)HY.1943-7900.0000497. 